Review

\title{
Function of Green Tea Catechins in the Brain: Epigallocatechin Gallate and its Metabolites
}

\author{
Monira Pervin ${ }^{1, *}$, Keiko Unno ${ }^{1, *}$, Akiko Takagaki ${ }^{2}$, Mamoru Isemura ${ }^{1}$ \\ and Yoriyuki Nakamura ${ }^{1}$ \\ 1 Tea Science Center, Graduate School of Integrated Pharmaceutical and Nutritional Sciences, \\ University of Shizuoka, Shizuoka 422-8526, Japan \\ 2 R\&D group, Mitsui Norin Co. Ltd., Shizuoka 426-0133, Japan \\ * Correspondence: gp1747@u-shizuoka-ken.ac.jp (M.P.); unno@u-shizuoka-ken.ac.jp (K.U.); \\ Tel./Fax: +81-54-264-5822 (M.P. \& K.U.)
}

Received: 3 July 2019; Accepted: 22 July 2019; Published: 25 July 2019

\begin{abstract}
Over the last three decades, green tea has been studied for its beneficial effects, including anti-cancer, anti-obesity, anti-diabetes, anti-inflammatory, and neuroprotective effects. At present, a number of studies that have employed animal, human and cell cultures support the potential neuroprotective effects of green tea catechins against neurological disorders. However, the concentration of (-)-epigallocatechin gallate (EGCG) in systemic circulation is very low and EGCG disappears within several hours. EGCG undergoes microbial degradation in the small intestine and later in the large intestine, resulting in the formation of various microbial ring-fission metabolites which are detectable in the plasma and urine as free and conjugated forms. Recently, in vitro experiments suggested that EGCG and its metabolites could reach the brain parenchyma through the blood-brain barrier and induce neuritogenesis. These results suggest that metabolites of EGCG may play an important role, alongside the beneficial activities of EGCG, in reducing neurodegenerative diseases. In this review, we discuss the function of EGCG and its microbial ring-fission metabolites in the brain in suppressing brain dysfunction. Other possible actions of EGCG metabolites will also be discussed.
\end{abstract}

Keywords: blood-brain barrier; catechin; cognition; epigallocatechin gallate; green tea; microbiota; 5-(3,5-dihydroxyphenyl)- $\gamma$-valerolactone

\section{Introduction}

Tea is derived from the leaves and buds of the plant Camellia sinensis L. (Theaceae). Among the different types of tea, such as green tea, black tea, and oolong tea, the health benefits of green tea have been most extensively studied [1,2]. These include anti-cancer [3,4], anti-obesity [5-7], anti-diabetes [8,9], and neuroprotective effects [10-12]. The antioxidant and metal chelating [13,14], anti-carcinogenic [15], anti-apoptotic [16,17], pro-apoptotic, and anti-inflammatory $[14,18]$ properties of catechins are greatly associated with their beneficial health effects, including suppressing neurodegenerative diseases.

Compared to other beverages, green tea is rich in catechins. According to Khokhar et al., $100 \mathrm{~mL}$ of green tea ( $1 \mathrm{~g}$ of dry tea leaves brewed for $5 \mathrm{~min}$ in $100 \mathrm{~mL}$ of hot water) contains on average $67 \pm 11 \mathrm{mg}$ of total catechins, including about $30 \mathrm{mg}$ of (-)-epigallocatechin gallate (EGCG), whereas black tea contains $15.4 \mathrm{mg}$ of catechins [19]. In green tea catechins, the main active molecule, EGCG (Figure 1), an ester of (-)-epigallocatechin (EGC) and gallic acid (GA), represents $50-80 \%$ of the total catechin content, followed by EGC, (-)-epicatechin gallate (ECG), (-)-epicatechin (EC), and (+)-catechin (C) [20]. Numerous beneficial effects of EGCG have been reported on cognitive function and oxidative damage [21-24]. Several epidemiological studies also showed the association between 
drinking tea and the beneficial effects on cognitive function [25-28]. For example, a cross-sectional study by Kuriyama et al. showed that daily ingestion of one or two cups of green tea significantly reduced cognitive impairment [25]. In another clinical study by Ide et al., the consumption of green tea ( $2 \mathrm{~g} /$ day) for 3 months significantly improved cognitive function and also reduced the progression of cognitive dysfunction [29].

Male Wistar rats that orally ingested EGCG showed a peak concentration at $1-2 \mathrm{~h}$ in systemic circulation, and it remained present in trace amounts after $4 \mathrm{~h}$ [30]. Much of orally ingested EGCG undergoes intestinal microbial degradation in the small intestine to EGC and GA, and later in the large intestine, resulting in the formation of various colonic microbial ring-fission metabolites, which are detectable in the plasma and urine [31-34]. These metabolites can exhibit biological activities, and some of them may be attributed to the action of EGCG.

This review discusses the function of EGCG and its metabolites as well as their possible action in the brain in suppressing brain dysfunction. In addition, recent data of other functions of EGCG metabolites are described.

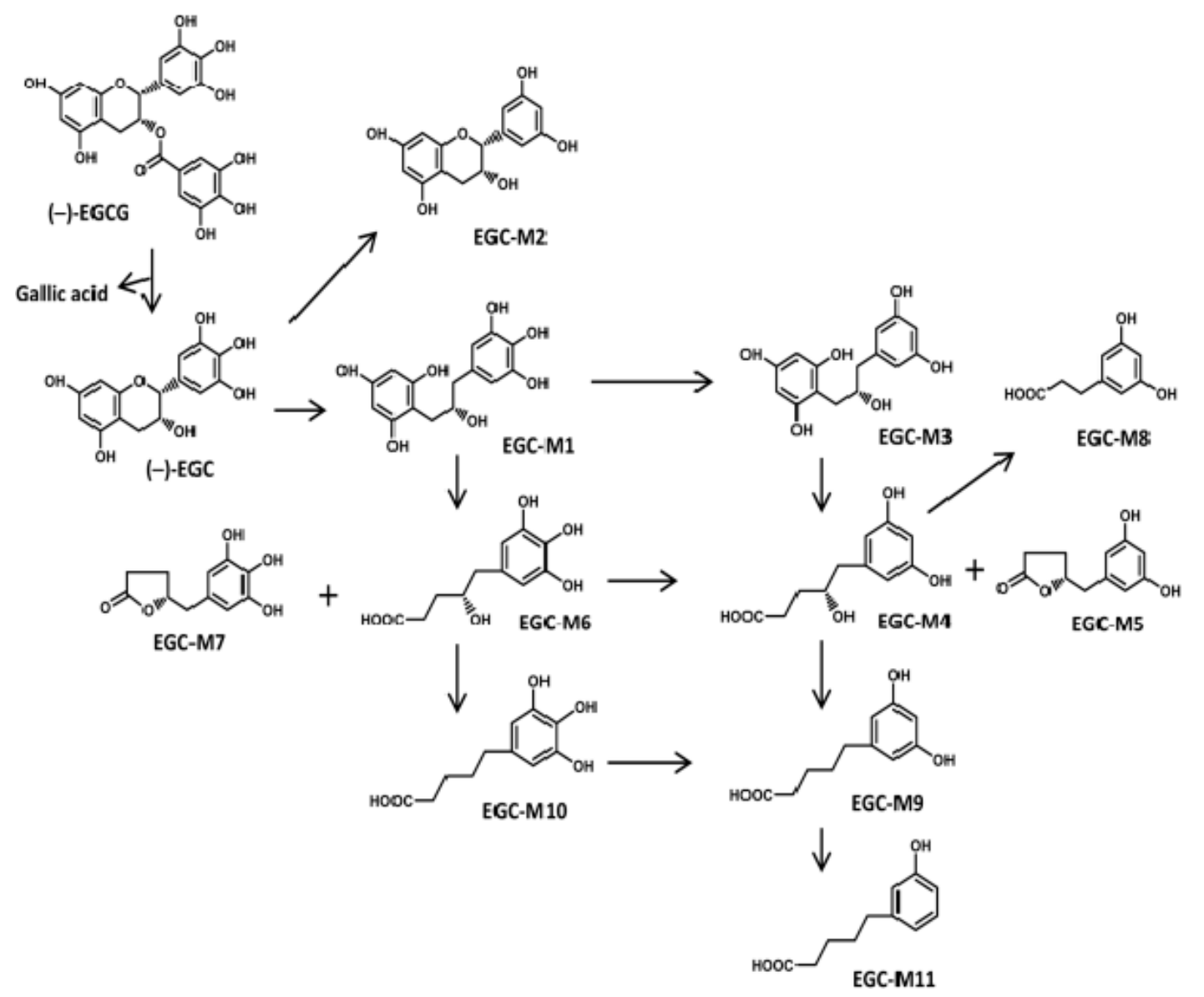

Figure 1. Chemical structures of EGCG metabolites based on data from Takagaki et al. [41].

\section{Bioactivity of EGCG and Its Metabolites in the Brain}

\subsection{Absorption and Bioavailability of EGCG}

EGCG is poorly absorbed by the body, it reaches the blood circulation at a very low micromolar concentration, and then it disappears from plasma within several hours [30,35-38]. The oral bioavailability of EGCG is estimated to be about 0.1 to $0.3 \%$ in rats and humans $[25,26,30,35]$. 


\section{Catechin Ring-Fission Products}

EGCG was found to be hydrolyzed by intestinal microbiota to produce EGC and GA. EGC was further degraded to some kinds of ring-fission metabolites in the gut tract. In the large intestine, there are 11 colonic microbial ring-fission metabolites of EGC (EGC-M1-M11) (Table 1, Figure 1) as described by Takagaki et al., i.e. 1-(3,4,5-trihydroxyphenyl) 3-(2,4,6-trihydroxyphenyl)-propan-2-ol (EGC-M1), 4-dehydroxylated epigallocatechin (EGC-M2), 1-(3,5-dihydroxyphenyl)- 3-(2,4,6trihydroxyphenyl)-propan-2-ol (EGC-M3), 4-hydroxy-5-(3,5-dihydroxyphenyl) valeric acid (EGC-M4), 5-(3,5-dihydroxyphenyl)- $\gamma$-valerolactone (EGC-M5), 4-hydroxy-5-(3,4,5-trihydroxyphenyl) valeric acid (EGC-M6), 5-(3,4,5-trihydroxyphenyl)- $\gamma$-valerolactone (EGC-M7), 3-(3,5-dihydroxyphenyl) propionic acid (EGC-M8), 5-(3,5-dihydroxyphenyl) valeric acid (EGC-M9), 5-(3,4,5-trihydroxyphenyl) valeric acid (EGC-M10), and 5-(3-hydroxyphenyl) valeric acid (EGC-M11) [39-41]. Among them, EGC-M5 and EGC-M7 were found to be the main metabolites in mice, rat, and human plasma, urine, and bile [42].

Table 1. Microbial ring-fission metabolites of EGCG in rat.

\begin{tabular}{cc}
\hline EGCG Metabolites (Microbial Ring-Fission) & Abbreviation \\
\hline 1-(3,4,5-trihydroxyphenyl)-3-(2,4,6-trihydroxyphenyl)-propan-2-ol & (EGC-M1) \\
4-dehydroxylated epigallocatechin & (EGC-M2) \\
1-(3,5-dihydroxyphenyl)-3-(2,4,6-trihydroxyphenyl)-propan-2-ol & (EGC-M3) \\
4-hydroxy-5-(3,5-dihydroxyphenyl) valeric acid & (EGC-M4) \\
5-(3,5-dihydroxyphenyl)- $\gamma$-valerolactone & (EGC-M5) \\
4-hydroxy-5-(3,4,5-trihydroxyphenyl) valeric acid & (EGC-M6) \\
5-(3,4,5-trihydroxyphenyl)- $\gamma$-valerolactone & (EGC-M7) \\
3-(3,5-dihydroxyphenyl) propionic acid & (EGC-M8) \\
5-(3,5-dihydroxyphenyl) valeric acid & (EGC-M9) \\
5-(3,4,5-trihydroxyphenyl) valeric acid & (EGC-M10) \\
5-(3-hydroxyphenyl) valeric acid & (EGC-M11) \\
\hline
\end{tabular}

Adapted from Takagaki et al. [41].

The intestinal microbial ring-fission metabolites of EGCG are present in plasma as free and conjugated forms [31], and in vitro data suggested that they could reach the brain parenchyma through the blood-brain barrier (BBB) and induce neuritogenesis [43], suggesting that they might be important in suppressing neurodegenerative diseases.

The bioavailability of a compound or its metabolites can be determined by quantifying the concentration at the systematic blood flow and at the target organ [44]. It is very important to know the metabolic process and bioavailability of green tea catechins to evaluate their biological activity as well as to understand their beneficial effects on human health. EGCG has much lower bioavailability than other components in catechins $[36,45]$. For example, after intragastric administration of decaffeinated green tea $(200 \mathrm{mg} / \mathrm{kg})$ to male Sprague-Dawley rats, $13.7 \%$ of EGC, $31.2 \%$ of EC, and $0.1 \%$ of EGCG appeared in the blood [36]. The bioavailability of EGCG is significantly different depending on the route of administration, such as intravenous, intragastric, or through peroral ingestion, since intravenously ingested EGCG can equally reach all tissues in a free state (without conjugate) compared to intragastric and peroral administration as a result of the high levels of EGCG in intravenous ingestion. It is much easier for tissues to absorb free EGCG (without conjugate) in intravenous ingestion compared to other routes of administration [38]. On the other hand, the absorption rate of EGCG in plasma was much better in peroral administration [46] compared to intragastric intubation, although the detailed mechanism is not clear [36]. Mice and rats show a difference in bioavailability. For example, in the mice model, there is higher absorption of EGCG (26.5\%) [38] than in the rat model (1.6\%) [36].

Aglycons (without sugar residues) from plant polyphenols are easily absorbed in the small intestine [47]. However, the majority of polyphenols in plants exist as a form of glycosides, esters, or polymers, and they cannot be absorbed directly from the intestine. Therefore, they are hydrolyzed by 
intestinal enzymes or gut microbiota. EGCG, the ester of epigallocatechin and GA, is metabolized by intestinal microbiota in rats $[39,40,48,49]$.

In mice, the bioavailability of a single dose of pure EGCG was first reported by Lambert et al. The authors found that after intravenous $(21.8 \mu \mathrm{mol} / \mathrm{kg})$ and intragastric $(163.8 \mu \mathrm{mol} / \mathrm{kg})$ administration of EGCG to male CF-1 mice, the plasma levels of total EGCG reached about $2.7 \pm 0.7$ and $0.28 \pm 0.08 \mu \mathrm{M}$, respectively. The levels of free EGCG in the liver, lung, small intestine, and colon were about 3.56, 2.66, 2.40 , and $1.20 \mathrm{nmol} / \mathrm{g}$, respectively. The levels of total EGCG in the small intestine and colon were 45.2 and $7.9 \mathrm{nmol} / \mathrm{g}$, but the levels in the liver and lung could not be determined as the concentration was too low [38]. On the other hand, in male Sprague-Dawley rats, the plasma bioavailability of EGCG was $0.1 \sim 1.6 \%$, suggesting that the rate of absorption in mice is much higher than in rats [36].

After $\left[4^{-3} \mathrm{H}\right] \mathrm{EGCG}(4 \mathrm{mg}, 7.4 \mathrm{MBq} / \mathrm{kg}$ ) was administered to male Wistar rats by intragastric gavage, the absorption, distribution, and excretion in blood, tissues, urine, and feces of EGCG and its metabolites were determined by tracing radioactivity using high-performance liquid chromatography (HPLC) analysis [31]. The results show that the radioactivity of EGCG mostly disappeared in the stomach by $72 \mathrm{~h}$. Peak radioactivity in the small intestine, cecum, and large intestine was detected at $4 \mathrm{~h}(40.5 \%$ of the dose), $8 \mathrm{~h}(46.4 \%$ of the dose), and $8 \mathrm{~h}(13.2 \%$ of the dose), respectively, and the radioactivity was markedly reduced by $24 \mathrm{~h}$ and had almost disappeared by $72 \mathrm{~h}$ in these tissues. The level of radioactivity in the blood was low at $4 \mathrm{~h}$, began to increase after $8 \mathrm{~h}$, peaked at $24 \mathrm{~h}$, and thereafter decreased. The urinary levels of two major radioactive metabolites, 5 -(5-hydroxyphenyl)- $\gamma$-valerolactone 3 - $O$ - $\beta$-glucuronide and EGC-M 5 were $68 \%$ and $16.8 \%$ of the ingested radioactivity after $48 \mathrm{~h}$. The authors suggested that intragastrically ingested EGCG is absorbed in the intestine within several hours $(<8 \mathrm{~h})$, and thereafter the EGCG metabolites and conjugates are absorbed from the large intestine ( $>8 \sim 48 \mathrm{~h}$ ), distributed to various tissues via blood circulation, and finally excreted via urine [31]. The degradation of EGCG by gut microbiota could be an important factor in decreasing its bioavailability [50]. When male C57BL/6J mice were given water containing (per $\mathrm{mL}$ ) ampicillin $(1 \mathrm{mg})$, sulfamethoxazole $(1.6 \mathrm{mg})$, and trimethoprim $(0.32 \mathrm{mg})$ for 11 days and then given a $0.32 \%$ Polyphenon E diet containing $643 \mathrm{mg}$ EGCG, $29 \mathrm{mg}$ EGC, $74 \mathrm{mg}$ ECG, $90 \mathrm{mg}$ EC, $45 \mathrm{mg}$ gallocatechin gallate, and $6 \mathrm{mg}$ caffeine per $\mathrm{g}$ of Polyphenon E, the levels of EGCG in blood, liver, and urine increased. On the other hand, antibiotic treatment decreased the urinary levels of EGC-M7, the ring-fission metabolites of EGCG, and 5-(3,4-dihydroxyphenyl)- $\gamma$-valerolactone, a ring-fission metabolite of EC. This finding suggests that antibiotic treatment eliminated catechin-degrading microbiota in the gut and therefore, increased the levels of EGCG as well as decreased the ring-fission metabolites due to the presence of a low content of microbiota in the gut [50].

In male Sprague-Dawley rats that were given EGCG orally at $150 \mathrm{mg} / \mathrm{kg}$, the plasma and the tissue distribution of EGCG were detected by developed HPLC with electrochemical detection [46]. After $2 \mathrm{~h}$ and $5 \mathrm{~h}$ of administration of EGCG, the levels of free (without conjugated) and total EGCG (with glucuronides, sulfates, and glucuronides/sulfates) in rat plasma were $0.7,0.28,0.82$, and $0.5 \mu \mathrm{M}$, respectively. The authors also reported unpublished data showing that the plasma level of EGCG in rats $24 \mathrm{~h}$ after administration is $0.05 \mu \mathrm{M}$, suggesting that the EGCG level was markedly reduced $24 \mathrm{~h}$ after administration. The tissue levels of free EGCG in the small intestine and colon were 21.15 and 10.75 , as well as 4.75 and $24.41 \mathrm{nmol} / \mathrm{g}$ at 2 and $5 \mathrm{~h}$, respectively. They showed that the levels of free EGCG in the kidney, liver, spleen, lung, and brain were 1.02 and $0.54,1.02$ and $0.54,0.1$ and $0.12,0.4$ and 0.14 , and 0.19 and $0.18 \mathrm{nmol} / \mathrm{g}$ at 2 and $5 \mathrm{~h}$, respectively. These results indicate that the levels of EGCG in plasma and other tissues were high at $2 \mathrm{~h}$ and began to decrease $5 \mathrm{~h}$ after administration. Moreover, the plasma level of EGCG was very low $24 \mathrm{~h}$ after ingestion [46].

A human study by Warden et al. showed that after drinking black tea containing $16.74 \mathrm{mg}$ of EGCG, $15.48 \mathrm{mg}$ of EGC, $36.54 \mathrm{mg}$ of EC, and $31.14 \mathrm{mg}$ of ECG, the plasma concentration of EGCG was at the peak level between 5 and $8 \mathrm{~h}$, but returned to baseline levels by $24 \mathrm{~h}$. After tea ingestion over $6 \mathrm{~h}$, the ingested catechins detected in plasma, urine, and feces were about $0.16 \%, 1.1 \%$, and $0.42 \%$, respectively, suggesting that level of absorption of catechins in humans is also quite low [51]. 
Microflora-mediated ring fission metabolites have also been identified in humans. EGCG was found to be hydrolyzed in the small intestine by intestinal microflora to produce EGC and GA and further degraded in the large intestine to produce various kinds of microbial ring fission metabolites $[34,52,53]$. In a human urinary metabolite profile, the ring-fission metabolites of tea catechins, such as 5-(3, 4-dihydroxyphenyl)- $\gamma$-valerolactone, EGC-M5, EGC-M7, and their glucuronide and sulfate conjugates, were found to be the major urinary metabolites at $12-24 \mathrm{~h}$ after ingestion of tea (200 $\mathrm{mL}$ of reconstituted green tea (from $3 \mathrm{~g}$ of tea solids)) in healthy male volunteers [34]. Two catechin ring-fission metabolites, EGC-M7 and 5-(3,4-dihydroxyphenyl)- $\gamma$-valerolactone, appeared in urine $(4-8 \mu \mathrm{M})$ and in plasma $(0.1-0.2 \mu \mathrm{M})$ approximately $13 \mathrm{~h}$ after ingestion of $20 \mathrm{mg} / \mathrm{kg}$ of decaffeinated green tea [53]. In addition, the cumulative urinary excretion of these microbial ring-fission metabolites was as high as 8-25 times the levels of ECG and EC [53]. A recent study on colonic ring-fission metabolism in humans identified various urinary metabolites derived from green tea flavan-3-ol ( $639 \mu \mathrm{mol}$ of monomeric catechin and $88 \mu \mathrm{mol}$ of oligomeric catechin), including EGC-M5, EGC-M7, 5-(4,5-dihydroxyphenyl)- $\gamma$-valerolactone, and 5-(hydroxyphenyl)- $\gamma$-valerolactone, with their glucuronide and sulphate conjugates [54]. The excretion rates of these ring-fission metabolites were as follows: EGC-M5-disulphate $(163 \mu \mathrm{mol})$, EGC-M5-glucuronide $(34.4 \mu \mathrm{mol})$, EGC-M7-sulphate $(27.7 \mu \mathrm{mol})$, EGC-M7-glucuronide $(12.1 \mu \mathrm{mol})$, methyl-EGC-M7-sulphate $(54.7 \mu \mathrm{mol})$, methyl-EGC-M7-glucuronide (2.7 $\mu \mathrm{mol}), \quad 5-(4,5-d i h y d r o x y p h e n y l)-\gamma$-valerolactone-disulphate (87.6 $\mu \mathrm{mol}), 5-(4,5$-dihydroxyphenyl)- $\gamma$-valerolactone-glucuronide $(16.8 \mu \mathrm{mol}), 5$-(hydroxyphenyl)- $\gamma$ valerolactone-sulphate $(19.7 \mu \mathrm{mol})$, and 5-(hydroxyphenyl)- $\gamma$-valerolactone-glucuronide (6.6 $\mu \mathrm{mol})$ [54]. In this study, the bioavailability of green tea flavan-3-ols was about $62 \%$ (the ratio between total metabolic excretion and total intake of flavan-3-ols) in $48 \mathrm{~h}$ which is higher than that reported previously (39\%) in $24 \mathrm{~h}$ [52]. This study examined a more complete $48 \mathrm{~h}$ metabolic excretion profile and quantified a wider range of colonic microbial metabolites [54].

\subsection{Blood-Brain Barrier Permeability of EGCG and Its Metabolites}

The BBB is a dynamic system that separates circulating peripheral blood from brain neural tissue in the central nervous system. It is composed of endothelial cells connected through gap junctional proteins, astrocytes, pericytes, and extracellular matrix and works together to regulate the movement of ions, molecules, and cells between the blood and the brain to create a unique microenvironment for proper neuronal function [55]. Therefore, the BBB plays a significant role in transporting intravascular substances into the brain.

After male Sprague-Dawley rats were administrated EGCG at $50 \mathrm{mg} / \mathrm{kg}$, the concentration of EGCG in various brain regions was measured by liquid chromatography tandem mass spectrometry (LC-MS/MS) [56]. The concentration of EGCG in various brain regions was about $5 \mathrm{ng} / \mathrm{mL}(0.01$ $\mu \mathrm{M})$ and $\sim 4.95 \%$ of the orally administered EGCG $(100 \mathrm{mg} / \mathrm{kg})$ reached the systemic circulation. However, it was unclear whether EGCG was transferred from blood vessels into the parenchyma [56]. The concentration of EGCG in rat brain tissue (extracted consecutively with ethyl acetate and methanol) was determined to be about $0.5 \mathrm{nmol} / \mathrm{g}$ by chemiluminescence-detection HPLC (CL-HPLC) at $60 \mathrm{~min}$ after oral administration $(500 \mathrm{mg} / \mathrm{kg})$ in male Sprague-Dawley rats [57].

When the blood-to brain distribution ratios of $C$ and EC which were administered $(20 \mathrm{mg} / \mathrm{kg})$ to male Sprague-Dawley rats via the femoral vein, which was measured by microdialysis sampling coupled with CL-HPLC, the ratios of C and EC were $0.0726 \pm 0.0376$ and $0.1065 \pm 0.0531$, respectively, as determined using the area under the curve for brain and blood [58]. In another study, the transport efficiency of $C$ and EC at $30 \mathrm{mM}$ was determined using two BBB cell lines, RBE-4 (rat brain endothelial cell) and hCMEC/D3 (human brain endothelial cell). Results showed that both C and EC effectively crossed the barrier in a time-dependent manner, and that the percentage of transport efficiency ( $\%$ in $1 \mathrm{~h})$ of EC (15.4 \pm 0.6$)$ was significantly higher than C (7.4 \pm 0.7$)$ [59].

Recently, we determined in vitro BBB permeability of EGCG and its metabolites (Table 2) by LC-MS/MS using a BBB kit (RBT-24, PharmaCo-Cell, Nagasaki, Japan) consisting of co-cultures of 
endothelial cells, pericytes, and astrocytes $[43,60]$. The in vitro BBB permeability ( $\%$, in $0.5 \mathrm{~h})$ of EGCG, EGC, and GA was $4.00 \pm 0.17,4.96 \pm 0.55$, and $9.42 \pm 1.01$, respectively (the data from [43] are modified). GA exhibited a higher permeability than EGCG and EGC, perhaps due to the smaller molecular size of GA (MW 170.12) compared to EGCG (MW 458.372) and EGC (MW 306.27). The BBB permeability of EGC was lower than that of EC, and between EC and C. Lower BBB permeability of EGC than that of EC may be due to one more hydroxyl bond of EGC than EC, which affects its permeability. On the other hand, BBB permeability may be influenced by the presence of hydrophobicity of the galloyl bond $[43,59,60]$.

The BBB permeability (\%, in $0.5 \mathrm{~h})$ of microbial ring-fission metabolites EGC-M5, and its conjugates, such as glucuronide of EGC-M5 (EGC-M5-GlcUA) and sulfate of EGC-M5 (EGC-M5-Sul), were $5.34 \pm 0.23,3.72 \pm 0.01$, and $4.34 \pm 0.40$, respectively. EGC-M5, with a smaller molecular size (MW 208.07), exhibited a slightly higher permeability than its conjugates EGC-M5-GlcUA (MW 384.11) and EGC-M5-Sul (MW 287.02), suggesting that the smaller molecular size of EGC-M5 caused its higher permeability [43].

Table 2. BBB permeability of EGCG metabolites.

\begin{tabular}{ccc}
\hline Sample & Permeability Coefficient $\left(\mathbf{1 0}^{-\mathbf{6}} \mathbf{c m ~ s}^{\mathbf{- 1}}\right)$ & BBB Permeability (\%) (30 min) \\
\hline EGCG & $13.45 \pm 0.57$ & $4.00 \pm 0.17$ \\
EGC & $16.70 \pm 1.86$ & $4.96 \pm 0.55$ \\
GA & $31.73 \pm 3.39$ & $9.42 \pm 1.01$ \\
EGC-M5 & $17.99 \pm 0.79$ & $5.34 \pm 0.23$ \\
EGC-M5-GlcUA & $12.53 \pm 0.02$ & $3.72 \pm 0.01$ \\
EGC-M5-Sul & $14.61 \pm 1.35$ & $4.34 \pm 0.40$ \\
PG & $13.79 \pm 1.62$ & $4.10 \pm 0.48$ \\
PG-GlcUA & $9.28 \pm 1.41$ & $2.76 \pm 0.42$ \\
\hline
\end{tabular}

Data are expressed as the mean $\pm \operatorname{SEM}(n=3)$ [43]. (Data of Ref. 43 are modified).

\subsection{Neuritogenic Activity of EGCG and Its Microbial Ring-Fission Metabolites}

Since EGCG and its microbial ring-fission metabolites were able to reach brain parenchyma through the $\mathrm{BBB}$, findings on how these bioactive compounds work in the brain and verification of their neuritogenic activity were needed. Human neuroblastoma SH-SY5Y cells (ATCC, CRL-2266) were used to assess neuritogenic activity as they are often used as in vitro models of neuronal function and differentiation [61]. In brief, SH-SY5Y cells were plated as $2.5 \times 10^{4}$ cells $/ \mathrm{mL}$ in a 24 -well plate $(500 \mu \mathrm{L}$ of cell suspension/well). EGCG and its metabolites, which were dissolved in $0.01 \% \mathrm{DMSO}$, were added to the culture medium to make a final concentration of $0.01-1.0 \mu \mathrm{M}$, and cultured for $\sim 72 \mathrm{~h}$. Neurite length was measured by ImageJ software (Ver. 1.50i) [43,60]. Neurite length was significantly prolonged in cells treated with EGCG and EGC-M5 at $0.05 \mu \mathrm{M}$ compared to control cells. In addition, SH-SY5Y cell growth was significantly enhanced by $0.05 \mu \mathrm{M}$ EGCG and its metabolites compared to control cells, but this effect was reduced at higher concentrations $(\geq 1.0 \mu \mathrm{M})$. Since the data of BBB permeability suggest that $4.0 \%(0.5 \mathrm{~h})$ of EGCG can pass through blood to brain parenchyma, it may be possible to speculate how much EGCG is needed in the blood for $\sim 0.05 \mu \mathrm{M}$ EGCG to reach the brain $[43,60]$. The plasma concentration of EGCG in humans is $0.02 \mu \mathrm{M}$ after drinking black tea containing $16.74 \mathrm{mg}$ of EGCG [51]. After a few hours of circulation of blood containing $0.02 \mu \mathrm{M}$ EGCG, its accumulation is $\sim 0.05 \mu \mathrm{M}$ in the brain. Although EGCG reaches in only trace amounts after $8 \mathrm{~h}$ or more of the EGCG intake, EGC-M5, a metabolite of EGCG, can be found in the blood. Whereas the levels of EGCG metabolites such as EGC-M5 and its conjugates in blood have not been determined, they are thought to be circulating in the blood for several hours. Since the BBB permeability of EGC-M5 is slightly higher than that of EGCG and the bioavailability of catechins is reported to be $39 \%$ in $24 \mathrm{~h}$ [52] and $62 \%$ in $48 \mathrm{~h}$ [54], EGC-M5 transferred from blood into the brain may also have a role in neuritogenesis. It is 
necessary to further investigate whether EGCG and its metabolites reach concentrations that cause neuritogenesis in vivo after consuming several cups of green tea per day in humans.

\section{Bioactivity of Catechin Ring-Fission Metabolites}

Catechin metabolites show several biological activities, including anti-oxidative, anti-inflammatory, anti-cancer, immunomodulatory, anti-thrombotic, and blood pressure-lowering activities (Table 3).

Table 3. Bioactivity of catechin metabolites.

\begin{tabular}{|c|c|c|}
\hline Catechin Metabolites & Bioactivity & Reference \\
\hline 5-(3,4-dihydroxyphenyl)- $\gamma$-valerolactone & Anti-oxidative & [63] \\
\hline 5-(3,4-dihydroxyphenyl)- $\gamma$-valerolactone & Anti-oxidative & [65] \\
\hline 5-(3-hydroxyphenyl)- $\gamma$-valerolactone & Anti-oxidative & [63] \\
\hline (EGC-M1) & Anti-cancer & [62] \\
\hline (EGC-M4) & Anti-oxidative & [63] \\
\hline (EGC-M5) & Antidiabetic effect & [41] \\
\hline (EGC-M5) & Neuritogenic activity & [43] \\
\hline (EGC-M5) & Blood-brain barrier penetrating activity & [43] \\
\hline (EGC-M5) & Anti-oxidative & [63] \\
\hline (EGC-M5) & Immunomodulatory activity & {$[66]$} \\
\hline (EGC-M5) & Blood pressure lowering activity & {$[67]$} \\
\hline (EGC-M6) & Antidiabetic effect & [41] \\
\hline (EGC-M6) & Anti-cancer & [62] \\
\hline (EGC-M7) & Antidiabetic effect & [41] \\
\hline (EGC-M7) & Anti-cancer & [64] \\
\hline (EGC-M7) & Anti-inflammatory & [64] \\
\hline (EGC-M7) & Blood pressure lowering activity & {$[67]$} \\
\hline (EGC-M9) & Anti-oxidative & [63] \\
\hline (EGC-M10) & Anti-oxidative & [63] \\
\hline (EGC-M10) & Anti-cancer & {$[62]$} \\
\hline (EGC-M11) & Antidiabetic effect & [41] \\
\hline (EGC-M11) & Anti-oxidative & [63] \\
\hline
\end{tabular}

Hara-Terawaki et al. evaluated anti-cancer effects of catechin metabolites against human cervical cancer cells (HeLa cells) [62]. The authors screened the inhibitory activities of 11 kinds of metabolites (EGC-M1-M11) produced from EGCG by intestinal microbiota on proliferation of HeLa cells. Among the 11 metabolites, EGC-M1, EGC-M6, and EGC-M10 inhibited the proliferation of HeLa cells at a final concentration of $50 \mu \mathrm{g} / \mathrm{mL}$ [62]. Another study by Takagaki et al. investigated the anti-oxidative activity of catechin metabolites by flow injection analysis coupled to an on-line antioxidant detection system with the 2, 20-azinobis (3-ethylbenzothiazoline-6-sulfonic acid) radical cation. The radical scavenging abilities of EGCG metabolites, such as EGC-M4, EGC-M5, EGC-M9, EGC-M10, and EGC-M11, as well as 5-(3, 4 dihydroxyphenyl)- $\gamma$-valerolactone, and 5-(3-hydroxyphenyl)- $\gamma$-valerolactone), which are ring-fission metabolites produced from EC or ECG, were found to be stronger than those of parental catechins [63]. Two ring-fission metabolites of tea catechins were tested for their anti-cancer and anti-inflammatory activities against a panel of immortalized and malignant human cell lines [64]. EGC-M7 had significantly strong inhibitory activity at $15-73 \mu \mathrm{M}$ than 5-(3,4-dihydroxyphenyl)- $\gamma$-valerolactone at $50 \mu \mathrm{M}$ against human colon cancer cells (HT-29 and HCT-116), human esophageal squamous cell carcinoma (KYSE150), human normal immortalized intestinal cells (INT-407), and rat intestinal epithelial cells (IEC-6). EGC-M7 also showed anti-inflammatory activity at $20 \mu \mathrm{M}$ by inhibiting nitric oxide production (50\%) in lipopolysaccharide (LPS)-stimulated murine macrophage (RAW264.7) cells [64]. The anti-oxidant activity of a ring-fission metabolite 5-(3,4-dihydroxyphenyl)- $\gamma$-valerolactone from (-)-epicatechin was described by Unno et al. [65]. In another study, EGC-M5 was found to have immunomodulatory activity by enhancing the activity of $\mathrm{CD}^{+} \mathrm{T}$ cells and the cytotoxic activity of natural killer cells in $\mathrm{BALB} / \mathrm{c}$ mice [66]. EGCG microbial metabolites were found to have blood pressure lowering activity 
in rats. A single oral intake of EGCG metabolites, EGC-M5 and EGC-M7, was examined to observe systolic blood pressure (SBP) using spontaneously hypertensive rats. There was a significant decrease in SBP $2 \mathrm{~h}$ after administration $(150 \mathrm{mg} / \mathrm{kg})$ of EGC-M7 and $4 \mathrm{~h}$ after administration $(200 \mathrm{mg} / \mathrm{kg})$ of EGC-M5, compared to the control group [67]. More recently, EGCG microbial metabolites were found to have antidiabetic effects in vitro and in vivo [41]. Glucose uptake ability of EGCG metabolites was measured with differentiated rat L6 myoblast cells by using 2-deoxyglucose. The treatment with EGC-M5, EGC-M6, EGC-M7, and EGC-M11 at $3 \mu \mathrm{M}$ for 15 min significantly increased glucose uptake by $164.2 \%, 165.2 \%, 167.6 \%$, and $146.3 \%$, respectively, compared to control cells [41]. Moreover, oral administration of EGC-M 5 at $32 \mathrm{mg} / \mathrm{kg}$ of body weight significantly suppressed postprandial hyperglycemia at $15 \mathrm{~min}(150.5 \pm 13.6 \mathrm{mg} / \mathrm{dL})$ and $30 \mathrm{~min}(108.5 \pm 17.2 \mathrm{mg} / \mathrm{dL})$ after oral glucose loading, compared to the saline control group [41].

The above studies indicate an important contribution of intestinal microflora-derived ring fission metabolites of catechins on protection against various diseases, including neurodegenerative diseases.

\section{Conclusions and Future Expectation}

Several studies including animal, human, and cell cultures support the potential neuroprotective activities of green tea catechins against neurological disorders. Very recently, EGCG was found to be safe and potential in improving cognition using both preclinical (mice) and clinical (human) studies [68]. The concentrations of EGCG, which is the main and the most active component among catechins, are very low in human and rat plasma and EGCG disappears within several hours from systemic circulation $(<8 \mathrm{~h}$ ) due to fast and extensive metabolism (methylation, glucuronidation, and sulfation) and microbial metabolism and degradation, resulting in the formation of various microbial ring-fission metabolites, which are detectable $(>8 \mathrm{~h})$ in the plasma and urine $[30,31,33]$. These microbial ring-fission metabolites show much higher bioavailability [52,55]. Intact EGCG and its metabolites reached the brain parenchyma through the $\mathrm{BBB}$ and induced neuritogenesis at a low concentration $(0.05 \mu \mathrm{M})[43,60]$.

Based on our and other findings, we propose a possible action of EGCG and its metabolites in the brain as follows. When humans drink green tea, intact EGCG at a very low micromolar level reaches the brain parenchyma through the BBB and may induce neurite outgrowth, and after EGCG disappears, metabolized EGCG may promote neurite outgrowth, resulting in the prevention of cognitive dysfunction $[43,60]$. On the other hand, EGCG and its metabolites that reached the brain may reduce oxidative damage, since the levels of lipid peroxidation were significantly reduced in the brain of senescence-accelerated mouse prone 10 (SAMP10) that ingested EGCG [60]. In addition, EGCG metabolites have anti-oxidant activity $[63,65]$. Thus, microbial ring-fission metabolites may play an important role in suppressing brain dysfunction. However, differences in intestinal microbiota may have great importance on the variability of metabolites as well as the absorption rate among humans [52-54,69]. To date, there are no findings on the neuroprotective action of microbial ring-fission metabolites of EGCG in vivo. It is becoming epidemiologically clear that intake of green tea suppresses cognitive decline $[11,70,71]$. In the future it will be necessary to examine not only the relationship between green tea intake and brain function but also the relationship between brain function and the concentrations of EGCG and its metabolites in the blood.

Author Contributions: M.P.-Corresponding author; Outline of whole manuscript; Literature search; Text preparation; K.U.-Corresponding author; Project design; Outline of whole manuscript; Text preparation; A.T.-Literature search; Text preparation; Preparation of Figure 1.; M.I.-Literature search; Outline of whole manuscript; Text preparation; Y.N.-Project design; Text preparation. All authors read and approved the final manuscript.

Funding: This research received no external funding.

Conflicts of Interest: The authors declare no conflict of interest. 


\section{References}

1. Miyoshi, N.; Pervin, M.; Suzuki, T.; Unno, K.; Isemura, M.; Nakamura, Y. Green tea catechins for well-being and therapy: Prospects and opportunities. Bot. Targets Ther. 2015, 5, 85-96.

2. Suzuki, T.; Miyoshi, N.; Hayakawa, S.; Imai, S.; Isemura, M.; Nakamura, Y. Health Benefits of Tea Consumption. In Beverage Impacts on Health and Nutrition, 2nd ed.; Wilson, T., Templ, N.J., Eds.; Springer International Publishing: Cham, Switzerland, 2016; pp. 49-67, ISBN 978-3-319-23672-8.

3. Carlson, J.R.; Bauer, B.A.; Vincent, A.; Limburg, P.J.; Wilson, T. Reading the tea leaves: Anticarcinogenic properties of (-)-epigallocatechin-3-gallate. Mayo Clin. Proc. 2007, 82, 725-732. [CrossRef]

4. Yang, C.S.; Wang, H. Cancer preventive activities of tea catechins. Molecules 2016, 21, 1679. [CrossRef] [PubMed]

5. Suzuki, T.; Pervin, M.; Goto, S.; Isemura, M.; Nakamura, Y. Beneficial effects of tea and the green tea catechin epigallocatechin-3-gallate on obesity. Molecules 2016, 21, 1305. [CrossRef] [PubMed]

6. Friedrich, M.; Petzke, K.J.; Raederstorff, D.; Wolfram, S.; Klaus, S. Acute effects of epigallocatechin gallate from green tea on oxidation and tissue incorporation of dietary lipids in mice fed a high-fat diet. Int. J. Obes. 2012, 36, 735-743. [CrossRef]

7. Lee, M.S.; Kim, C.T.; Kim, Y. Green tea (-)-epigallocatechin-3-gallate reduces body weight with regulation of multiple genes expression in adipose tissue of diet-induced obese mice. Ann. Nutr. Metab. 2009, 54, 151-157. [CrossRef]

8. Lombo, C.; Morgado, C.; Tavares, I.; Neves, D. Effects of prolonged ingestion of epigallocatechin gallate on diabetes type 1-induced vascular modifications in the erectile tissue of rats. Int. J. Impot. Res. 2016, 28, 133-138. [CrossRef]

9. Othman, A.I.; El-Sawi, M.R.; El-Missiry, M.A.; Abukhalil, M.H. Epigallocatechin-3-gallate protects against diabetic cardiomyopathy through modulating the cardiometabolic risk factors, oxidative stress, inflammation, cell death and fibrosis in streptozotocin-nicotinamide-induced diabetic rats. Biomed. Pharmacother. 2017, 94, 362-373. [CrossRef]

10. Yokogoshi, H. Green tea in the protection against neurodegeneration. In Health Benefits of Green Tea: An Evidence-Based Approach, 1st ed.; Hara, Y., Yang, C.S., Isemura, M., Tomita, I., Eds.; CABI International: Oxfordshire, UK, 2016; pp. 185-229, ISBN 978-178639-239-8.

11. Pervin, M.; Unno, K.; Ohishi, T.; Tanabe, H.; Miyoshi, N.; Nakamura, Y. Beneficial effects of green tea catechins on neurodegenerative diseases. Molecules 2018, 23, 1297. [CrossRef]

12. Xicota, L.; Rodriguez-Morato, J.; Dierssen, M.; de la Torre, R. Potential Role of (-)-Epigallocatechin-3-Gallate (EGCG) in the Secondary Prevention of Alzheimer Disease. Curr. Drug Targets 2017, 2, 174-195. [CrossRef]

13. Yang, Y.; Qin, Y.J.; Yip, Y.W.Y.; Chan, K.P.; Chu, K.O.; Chu, W.K.; Ng, T.K.; Pang, C.P.; Chan, S.O. Green tea catechins are potent anti-oxidants that ameliorate sodium iodate-induced retinal degeneration in rats. Sci. Rep. 2016, 6, 29546. [CrossRef] [PubMed]

14. Cavet, M.E.; Harrington, K.L.; Vollmer, T.R.; Ward, K.W.; Zhang, J.Z. Anti-inflammatory and anti-oxidative effects of the green tea polyphenol epigallocatechin gallate in human corneal epithelial cells. Mol. Vis. 2011, 17, 533-542. [PubMed]

15. Xiang, L.P.; Wang, A.; Ye, J.H.; Zheng, X.Q.; Polito, C.A.; Lu, J.L.; Li, Q.S.; Liang, Y.R. Suppressive effects of tea catechins on breast cancer. Nutrients 2016, 8, 458. [CrossRef]

16. Ding, M.L.; Ma, H.; Man, Y.G.; Lv, H.Y. Protective effects of a green tea polyphenol, epigallocatechin-3-gallate, against sevoflurane-induced neuronal apoptosis involve regulation of CREB/BDNF/TrkB and PI3K/Akt/mTOR signalling pathways in neonatal mice. Can. J. Physiol. Pharmacol. 2017, 95, 1396-1405. [CrossRef] [PubMed]

17. He, Y.; Tan, D.; Bai, B.; Wu, Z.; Ji, S. Epigallocatechin-3-gallate attenuates acrylamide-induced apoptosis and astrogliosis in rat cerebral cortex. Toxicol. Mech. Methods 2017, 27, 298-306. [CrossRef] [PubMed]

18. Liu, D.; Perkins, J.T.; Hennig, B. EGCG prevents PCB-126-induced endothelial cell inflammation via epigenetic modifications of NF-kB target genes in human endothelial cells. J. Nutr. Biochem. 2016, 28, 164-170. [CrossRef]

19. Khokhar, S.; Magnusdottir, S.G. Total phenol, catechin, and caffeine contents of teas commonly consumed in the United Kingdom. J. Agric. Food Chem. 2002, 50, 565-570. [CrossRef]

20. Khan, N.; Mukhtar, H. Tea polyphenols for health promotion. Life Sci. 2007, 81, 519-533. [CrossRef] 
21. Chang, X.; Rong, C.; Chen, Y.; Yang, C.; Hu, Q.; Mo, Y.; Zhang, C.; Gu, X.; Zhang, L.; He, W.; et al. (-)-Epigallocatechin-3-gallate attenuates cognitive deterioration in Alzheimer's disease model mice by upregulating neprilysin expression. Exp. Cell. Res. 2015, 334, 136-145. [CrossRef]

22. Unno, K.; Takabayashi, F.; Kishido, T.; Oku, N. Suppressive effect of green tea catechins on morphologic and functional regression of the brain in aged mice with accelerated senescence (SAMP10). Exp. Gerontol. 2004, 39, 1027-1034. [CrossRef]

23. Unno, K.; Takabayashi, F.; Yoshida, H.; Choba, D.; Fukutomi, R.; Kikunaga, N.; Kishido, T.; Oku, N.; Hoshino, M. Daily consumption of green tea catechin delays memory regression in aged mice. Biogerontology 2007, 8, 89-95. [CrossRef] [PubMed]

24. Unno, K.; Ishikawa, Y.; Takabayashi, F.; Sasaki, T.; Takamori, N.; Iguchi, K.; Hoshino, M. Daily ingestion of green tea catechins from adulthood suppressed brain dysfunction in aged mice. Biofactors 2008, 34, $263-271$. [CrossRef]

25. Kuriyama, S.; Hozawa, A.; Ohmori, K.; Shimazu, T.; Matsui, T.; Ebihara, S.; Awata, S.; Nagatomi, R.; Arai, H.; Tsuji, I. Green tea consumption and cognitive function: A cross-sectional study from the Tsurugaya Project 1. Am. J. Clin. Nutr. 2006, 83, 355. [CrossRef] [PubMed]

26. Noguchi-Shinohara, M.; Yuki, S.; Dohmoto, C.; Ikeda, Y.; Samuraki, M.; Iwasa, K.; Yokogawa, M.; Asai, K.; Komai, K.; Nakamura, H.; et al. Consumption of green tea, but not black tea or coffee, is associated with reduced risk of cognitive decline. PLoS ONE 2014, 9, e96013. [CrossRef] [PubMed]

27. Feng, L.; Gwee, X.; Kua, E.H.; Ng, T.P. Cognitive function and tea consumption in community dwelling older Chinese in Singapore. J. Nutr. Health Aging 2010, 14, 433-438. [CrossRef] [PubMed]

28. Gu, Y.J.; He, C.H.; Li, S.; Zhang, S.Y.; Duan, S.Y.; Sun, H.P.; Shen, Y.P.; Xu, Y.; Yin, J.Y.; Pan, C.W. Tea consumption is associated with cognitive impairment in older Chinese adults. Aging Ment. Health 2018, 22, 1232-1238. [CrossRef] [PubMed]

29. Ide, K.; Yamada, H.; Takuma, N.; Park, M.; Wakamiya, N.; Nakase, J.; Ukawa, Y.; Sagesaka, Y.M. Green tea consumption affects cognitive dysfunction in the elderly: A pilot study. Nutrients 2014, 6, 4032-4042. [CrossRef]

30. Unno, T.; Takeo, T. Absorption of (-)-epigallocatechin gallate into the circulation system of rats. Biosci. Biotechnol. Biochem. 1995, 59, 1558-1559. [CrossRef]

31. Kohri, T.; Matsumoto, N.; Yamakawa, M.; Suzuki, M.; Nanjo, F.; Hara, Y.; Oku, N. Metabolic fate of (-)-[4-(3)H] epigallocatechin gallate in rats after oral administration. J. Agric. Food Chem. 2001, 49, 4102-4112. [CrossRef]

32. Clifford, M.N.; van der Hooft, J.J.; Crozier, A. Human studies on the absorption, distribution, metabolism, and excretion of tea polyphenols. Am. J. Clin. Nutr. 2013, 98, 1619S-1630S. [CrossRef]

33. Stalmach, A.; Troufflard, S.; Serafini, M.; Crozier, A. Absorption, metabolism and excretion of Choladi green tea flavan-3-ols by humans. Mol. Nutr. Food Res. 2009, 53, S44-S53. [CrossRef] [PubMed]

34. Sang, S.; Lee, M.J.; Yang, I.; Buckley, B.; Yang, C.S. Human urinary metabolite profile of tea polyphenols analyzed by liquid chromatography/electrospray ionization tandem mass spectrometry with data-dependent acquisition. Rapid Commun. Mass. Spectrom. 2008, 22, 1567-1578. [CrossRef] [PubMed]

35. Nakagawa, K.; Miyazawa, T. Chemiluminescence-high performance liquid chromatographic determination of tea catechin, (-)-epigallocatechin 3-gallate, at picomole levels in rat and human plasma. Anal. Biochem. 1997, 248, 41-49. [CrossRef]

36. Chen, L.; Lee, M.J.; Li, H.; Yang, C.S. Absorption, distribution, and elimination of tea polyphenols in rats. Drug Metab. Dispos. 1997, 25, 1045-1050. [PubMed]

37. Zhu, M.; Chen, Y.; Li, R.C. Oral absorption and bioavailability of tea catechins. Planta Med. 2000, 66, 444-447. [CrossRef] [PubMed]

38. Lambert, J.D.; Lee, M.J.; Lu, H.; Meng, X.; Hong, J.J.; Seril, D.N.; Sturgill, M.G.; Yang, C.S. Epigallocatechin-3-gallate is absorbed but extensively glucuronidated following oral administration to mice. J. Nutr. 2003, 133, 4172-4177. [CrossRef] [PubMed]

39. Takagaki, A.; Nanjo, F. Metabolism of (-)-epigallocatechin gallate by rat intestinal flora. J. Agric. Food Chem. 2010, 58, 1313-1321. [CrossRef]

40. Takagaki, A.; Kato, Y.; Nanjo, F. Isolation and characterization of rat intestinal bacteria involved in biotransformation of (-)-epigallocatechin. Arch. Microbiol. 2014, 196, 681-695. [CrossRef] 
41. Takagaki, A.; Yoshioka, Y.; Yamashita, Y.; Nagano, T.; Ikeda, M.; Hara-Terawaki, A.; Seto, R.; Ashida, H. Effects of microbial metabolites of (-)-epigallocatechin gallate on glucose uptake in L6 skeletal muscle cell and glucose tolerance in ICR mice. Biol. Pharm. Bull. 2019, 42, 212-221. [CrossRef]

42. Feng, W.Y. Metabolism of green tea catechins: An overview. Curr. Drug Metab. 2006, 7, 755-809. [CrossRef]

43. Unno, K.; Pervin, M.; Nakagawa, A.; Iguchi, K.; Hara, A.; Takagaki, A.; Nanjo, F.; Minami, A.; Nakamura, Y. Blood-brain barrier permeability of green tea catechin metabolites and their neuritogenic activity in human neuroblastoma SH-SY5Y cells. Mol. Nutr. Food Res. 2017, 61, 1700294. [CrossRef] [PubMed]

44. Peterson, B.; Weyers, M.; Steenekamp, J.H.; Steyn, J.D.; Gouws, C.; Hamman, J.H. Drug bioavailability enhancing agents of natural origin (bioenhancers) that modulate drug membrane permeation and pre-systemic metabolism. Pharmaceutics 2019, 11, 33. [CrossRef] [PubMed]

45. Kim, S.; Lee, M.J.; Hong, J.; Li, C.; Smith, T.J.; Yang, G.Y.; Seril, D.N.; Yang, C.S. Plasma and tissue levels of tea catechins in rats and mice during chronic consumption of green tea polyphenols. Nutr. Cancer 2000, 37, 41-48. [CrossRef] [PubMed]

46. Raneva, V.G.; Shimizu, Y.; Shimasaki, H. Antioxidant activity in plasma and tissues distribution of (-)-epigallocatechin gallate after oral administration to rats. J. Oleo Sci. 2005, 54, 289-298. [CrossRef]

47. Pandey, K.B.; Rizvi, S.I. Plant polyphenols as dietary antioxidants in human health and disease. Oxid. Med. Cell. Longev. 2009, 2, 270-278. [CrossRef] [PubMed]

48. Takagaki, A.; Nanjo, F. Catabolism of (+)-catechin and (-)-epicatechin by rat intestinal microbiota. J. Agric. Food Chem. 2013, 61, 4927-4935. [CrossRef] [PubMed]

49. Takagaki, A.; Nanjo, F. Bioconversion of (-)-epicatechin, (+)-epicatechin, (-)-catechin, and (+)-catechin by (-)-epigallocatechinmetabolizing bacteria. Biol. Pharm. Bull. 2015, 38, 789-794. [CrossRef]

50. Liu, A.B.; Tao, S.; Lee, M.J.; Hu, Q.; Meng, X.; Lin, Y.; Yang, C.S. Effects of gut microbiota and time of treatment on tissue levels of green tea polyphenols in mice. Biofactors 2018, 44, 348-360. [CrossRef]

51. Warden, B.A.; Smith, L.S.; Beecher, G.R.; Balentine, D.A.; Clevidence, B.A. Catechins are bioavailable in men and women drinking black tea throughout the day. J. Nutr. 2001, 131, 1731-1737. [CrossRef]

52. Del Rio, D.; Calani, L.; Cordero, C.; Salvantore, S.; Pellegrini, N.; Brighenti, F. Bioavailability and catabolism of green tea flavan-3-ols in humans. Nutrition 2010, 26, 1110-1116. [CrossRef]

53. Li, C.; Lee, M.J.; Sheng, S.; Meng, X.; Prabhu, S.; Winnik, B.; Huang, B.; Chung, J.Y.; Yan, S.; Ho, C.T.; et al. Structural identification of two metabolites of catechins and their kinetics in human urine and blood after tea ingestion. Chem. Res. Toxicol. 2000, 13, 177-184. [CrossRef] [PubMed]

54. Calani, L.; Del Rio, D.; Luisa Callegari, M.; Morelli, L.; Brighenti, F. Updated bioavailability and 48 h excretion profile of flavan-3-ols from green tea in humans. Int. J. Food Sci. Nutr. 2012, 63, 513-521. [CrossRef] [PubMed]

55. Daneman, R.; Prat, A. The blood-brain barrier. Cold. Spring Harb. Perspect. Biol. 2015, 7, a020412. [CrossRef] [PubMed]

56. Lin, L.C.; Wang, M.N.; Tseng, T.Y.; Sung, J.S.; Tsai, T.H. Pharmacokinetics of (-)-epigallocatechin-3-gallate in conscious and freely moving rats and its brain regional distribution. J. Agric. Food Chem. 2007, 55, 1517-1524. [CrossRef] [PubMed]

57. Nakagawa, K.; Miyazawa, T. Absorption and distribution of tea catechin, (-)-epigallocatechin-3-gallate, in the rat. J. Nutr. Sci. Vitaminol. 1997, 43, 679-684. [CrossRef] [PubMed]

58. Wu, L.; Zhang, Q.L.; Zhang, X.Y.; Lv, C.; Li, J.; Yuan, Y.; Yin, F.X. Pharmacokinetics and blood-brain barrier penetration of (+)-catechin and (-)-epicatechin in rats by microdialysis sampling coupled to high-performance liquid chromatography with chemiluminescence detection. J. Agric. Food Chem. 2012, 60, 9377-9383. [CrossRef]

59. Faria, A.; Pestana, D.; Teixeira, D.; Couraud, P.O.; Romero, I.; Weksler, B.; de Freitas, V.; Mateus, N.; Calhau, C. Insights into the putative catechin and epicatechin transport across blood-brain barrier. Food Funct. 2011, 2, 39-44. [CrossRef]

60. Pervin, M.; Unno, K.; Nakagawa, A.; Takahashi, Y.; Iguchi, K.; Yamamoto, H.; Hoshino, M.; Hara, A.; Takagaki, A.; Nanjo, F.; et al. Blood brain barrier permeability of (-)-epigallocatechin gallate, its proliferation-enhancing activity of human neuroblastoma SH-SY5Y cells, and its preventive effect on age-related cognitive dysfunction in mice. Biochem. Biophys. Rep. 2017, 9, 180-186. [CrossRef]

61. Price, R.D.; Oe, T.; Yamaji, T.; Matsuoka, N. A simple, flexible, nonfluorescent system for the automated screening of neurite outgrowth. J. Biomol. Screen. 2006, 11, 155-164. [CrossRef] 
62. Hara-Terawaki, A.; Takagaki, A.; Kobayashi, H.; Nanjo, F. Inhibitory activity of catechin metabolites produced by intestinal microbiota on proliferation of HeLa cells. Biol. Pharm. Bull. 2017, 40, 1331-1335. [CrossRef]

63. Takagaki, A.; Otani, S.; Nanjo, F. Antioxidative activity of microbial metabolites of (-)-epigallocatechin gallate produced in rat intestines. Biosci. Biotechnol. Biochem. 2011, 75, 582-585. [CrossRef] [PubMed]

64. Lambert, J.D.; Rice, J.E.; Hong, J.; Hou, Z.; Yang, C.S. Synthesis and biological activity of the tea catechin metabolites, M4 and M6 and their methoxy-derivatives. Bioorg. Med. Chem. Lett. 2005, 15, 873-876. [CrossRef] [PubMed]

65. Unno, T.; Tamemoto, K.; Yayabe, F.; Kakuda, T. Urinary excretion of 5-(3',4'-dihydroxyphenyl)gamma-valerolactone, a ring-fission metabolite of (-)-epicatechin, in rats and its in vitro antioxidant activity. J. Agric. Food Chem. 2003, 51, 6893-6898. [CrossRef] [PubMed]

66. Kim, Y.H.; Won, Y.S.; Yang, X.; Kumazoe, M.; Yamashita, S.; Hara, A.; Takagaki, A.; Goto, K.; Nanjo, F.; Tachibana, H. Green tea catechin metabolites exert immunoregulatory effects on $\mathrm{CD} 4{ }^{(+)} \mathrm{T}$ cell and natural killer cell activities. J. Agric. Food Chem. 2016, 64, 3591-3597. [CrossRef] [PubMed]

67. Takagaki, A.; Nanjo, F. Effects of metabolites produced from (-)-epigallocatechin gallate by rat intestinal bacteria on angiotensin I-converting enzyme activity and blood pressure in spontaneously hypertensive rats. J. Agric. Food Chem. 2015, 63, 8262-8266. [CrossRef] [PubMed]

68. de la Torre, R.; de Sola, S.; Farré, M.; Xicota, L.; Cuenca-Royo, A.; Rodriguez, J.; León, A.; Langohr, K.; Gomis-González, M.; Hernandez, G.; et al. A phase 1, randomized double-blind, placebo controlled trial to evaluate safety and efficacy of epigallocatechin-3-gallate and cognitive training in adults with Fragile $\mathrm{X}$ syndrome. Clin. Nutr. 2019. [CrossRef] [PubMed]

69. Lee, H.C.; Jenner, A.M.; Low, C.S.; Lee, Y.K. Effect of tea phenolics and their aromatic fecal bacterial metabolites on intestinal microbiota. Res. Microbiol. 2006, 157, 876-884. [CrossRef]

70. Kakutani, S.; Watanabe, H.; Murayama, N. Green tea intake and risks for dementia, Alzheimer's disease, mild cognitive impairment, and cognitive impairment: A systematic review. Nutrients 2019, 11, 1165. [CrossRef]

71. Mancini, E.; Beglinger, C.; Drewe, J.; Zanchi, D.; Lang, U.E.; Borgwardt, S. Green tea effects on cognition, mood and human brain function: A systematic review. Phytomedicine 2017, 34, 26-37. [CrossRef]

(C) 2019 by the authors. Licensee MDPI, Basel, Switzerland. This article is an open access article distributed under the terms and conditions of the Creative Commons Attribution (CC BY) license (http://creativecommons.org/licenses/by/4.0/). 